\title{
Purification and characterization of two inducible exopolygalacturonases from Aspergillus kawachii
}

\author{
C.E. Byrne, S.F. Cavalitto*, C.E. Voget \\ Research and Development Center for Industrial Fermentations, CINDEFI (CCT-La Plata, CONICET-UNLP), Calle 47 y 115, B1900ASH La Plata, Argentina
}

\section{ARTICLE INFO}

\section{Keywords:}

Aspergillus kawachii

Exopolygalacturonases

Pectin degradation

\begin{abstract}
A B S T R A C T
Of two exopolygalacturonases purified and characterized from an Aspergillus kawachii culture grown on lemon pomace, the main one, exoPG1, was a glycosylated protein with a molecular mass of $75 \mathrm{kDa}$, isoelectric point in the 4.00-4.65 pH range, and a 3.0-4.0 pH optimum, though with activity at pH 2.0. ExoPG1 cleaved monomer units irrespective of the degree of substrate polymerization. Di- and trigalacturonic acids were completely hydrolyzed, whereas polygalacturonic acid (PGA) only incompletely. ExoPG1, along with a recombinant endoPG from the same fungal strain, was necessary for the hydrolysis of PGA down to the monomer. pH stability was maximum in the range 4.0-5.0 irrespective of the incubation temperature and decreased as the temperature increased from 30 to $70{ }^{\circ} \mathrm{C}$. The enzyme appeared not to require divalent cations for activity. Protein identification by MALDI-TOF-TOF MS/MS indicated homology of exoPG1 with the exopolygalacturonase PGXB of Aspergillus. niger, an exopolygalacturonase of Aspergillus tubingensis, and the exopolygalacturonase $\mathrm{X}$ of Aspergillus kawachii, a hypothetical enzyme predicted from the complete sequencing of the genome of the fungus. Both these latter proteins are unusual in that they have identical primary sequences. We therefore conclude that exoPG1 is probably the hypothetical A. kawachii exopolygalacturonase X. ExoPG2-having a molecular weight of $80 \mathrm{kDa}$, an isoelectricpoint between pHs 4.5 and 5.0, a 4.0 pH optimum, and kinetics with PGA similar to those of exoPG1—shared similarities with the exopolygalacturonase PGXC of $A$. niger and another proposed exopolygalacturonase of $A$. kawachii. This report is the first concerning exopolygalacturonases from A. kawachii.
\end{abstract}

\section{Introduction}

Aspergillus kawachii (white koji mold) has traditionally been used in Japan for the preparation of koji, the fermentation starter used for the production of the distilled alcoholic beverage shochu (Yoshizaki et al., 2010). Recently, the complete genomic sequence of the strain IFO 4308 was determined, and the analysis confirms that this mold is a major producer of polysaccharide-glycoside hydrolases (Futagami et al., 2011). Aspergillus kawachii has another relevant feature in the production of large amounts of citric acid during the brewing process that generates the moromi (the fermentative mash)_generating a highly acidic environment that prevents the growth of undesirable microorganisms. acidity im- plies that the saccharification has to be carried out by acid-stable enzymes-the most studied from A. kawachii (mainly from strain IFO 4308) being the amylases since those, along with the proteases, are primarily responsible for transforming the starch and proteins in rice, barley, or potatoes into a yeast-fermentable mash (Mikami et al., 1987; Yagi et al., 1986; Iwano et al., 1986; Kaneko et al., 1996; Morimura et al., 1999). Nevertheless, plant-cell-wall-degrading enzymes, or other specific glycosidases, can contribute significantly to the overall result of this fermentation process, since those catalytic activities facilitate the extraction of substrates for subsequent digestion by amylases and proteases, increase the overall yield, improve the availability of nutrients, and possibly even hydrolyze flavor-precursor compounds (Yoshizaki et al., 2010).

Corresponding author.

Email address: cavalitto@quimica.unlp.edu.ar (S.F. Cavalitto) 
Some of these enzymes - such as the B-D-glucosidases (Iwashita et al., 1998, 1999), endo-1,4-ß-xylanases (Ito et al., 1992; Crous et al., 1995), polygalacturonases (Kojima et al., 1999; Contreras Esquivel and Voget, 2004; Voget et al., 2006), $\alpha$-L-arabinofuranosidases (Koseki et al., 2003), $\alpha$-L-rhamnosidase (Koseki et al., 2008b), and endoglucanases (Hara et al., 2003; Koseki et al., 2008a)—have been purified, and the analysis of their kinetic properties has revealed that most are active at low pHs (ranging between 2.0 and 4.0). A variety of acidic pectinases and glycosidases were found to be induced when $A$. kawachii was grown with pectin or lemon pomace (LP) as the carbon sources (Vita et al., 2009). An interest in the enzymes of $A$. kawachii lies not only in an understanding of their role in the fermentation to produce shochu, but also in their potential use in biotechnological processes requiring acidophilic enzymes (Tenkanen et al., 1997; Dunn-Coleman et al., 2007; Sujimoto et al., 2012). Previous studies have shown that $A$. kawachii produces, in media containing glucose, pectin, or pectin-rich substrates such as LP, polygalacturonases (PGs) that remain active at pHs between 2.0 and 2.2 (i.e., possessing PG2 activity). From a glucose-containing culture, a constitutive endoPG (EC 3.2.1.15)—designated as endoPG1 and representing $>95 \%$ of the PG2 activity present in the culture filtrate-was purified, partially characterized, and subsequently cloned in $S$. cerevisiae (Contreras Esquivel and Voget, 2004; Rojas et al., 2011). EndoPG1 was not active at pH 5.0 - in contrast to most fungal PGs-hydrolyzed polygalacturonic acid (PGA) through a processive (endo/exo) mechanism, and could solubilize pectin from insoluble substrates such as protopectin or lemon wastes as well as macerate plant tissues at low pHs $(\sim 2.0)$. In LP medium, however, the greatest PG2 activity found in the culture filtrate was attributed to the presence of inducible acid-tolerant PGs (Vita et al., 2009). In the present study, we have demonstrated that the PG2 activity induced in LP media corresponds to two exopolygalacturonases: exoPGs, EC 3.2.1.67, designated as exoPG1 (the main acidic inducible exo-PG) and exoPG2. Both enzymes were purified to homogeneity as judged by sodium-dodecyl-sulfate-polyacrylamide-gel electrophoresis (SDS-PAGE) and were then further characterized. The role of exo-PGs in the nutrition of the fungus is obviously associated with the possibility to use pectin as the carbon source. From a biotechnological point of view, exo-PGs, in association with endo-PG, could be used along with pectin methylesterases for obtaining galacturonic acid from pectin-rich agro wastes. Galacturonic acid has otherwise found several potential applications as an intermediate for nonionic biodegradable surfactants (Laurent et al., 2011) and the production of vitamin C (Kulbe et al., 1987; Kuivanen et al., 2012).

\section{Materials and methods}

\subsection{Chemicals}

Galacturonic (GA), digalacturonic (DGA), trigalacturonic (TGA), and polygalacturonic (PGA) acids, citrus pectin (degree of methylation, 53\%) were from Sigma Chemicals (St. Louis, MO, USA). Coomassie Brilliant Blue G-250 was from Merck (Darmstadt, Germany). The recombinant endoPG1 polygalacturonase was produced in our laboratory. A solution of recombinant endoPG1 containing $2400 \mathrm{mU} / \mathrm{ml}$ was prepared in $20 \mathrm{mM} \mathrm{Na}$ acetate, $\mathrm{pH}$ 5.0. The chemicals for column chromatography and electrophoresis were from GE Healthcare Life Sciences (Chicago, USA).

\subsection{Microorganism, culture conditions, and biomass separation}

The fungal strain A. kawachii IFO 4308 was kindly provided by Prof. Takuo Sakai (Osaka Prefecture University, Osaka, Japan).
The medium containing lemon (Citrus limon, Burm. f.) pomace and the conditions for the shaker-flask cultures have been previously described (Voget et al., 2006). The enzyme was purified from a 30-h culture. The fungal mycelium was separated by passage through a cheese cloth followed by filtration through a $0.45-\mu \mathrm{m}$ cellulose-nitrate membrane (Sartorius, Goettingen, Germany). The culture filtrate was stored frozen at $-20{ }^{\circ} \mathrm{C}$.

\subsection{ExoPG1 and exoPG2 purification (cf. Table 1)}

\section{(i) Initial concentration}

The culture filtrate $(800 \mathrm{ml})$ was thawed and concentrated $25 \times$ under reduced pressure for $6 \mathrm{~h}$ at $35^{\circ} \mathrm{C}$ and $\mathrm{pH} 3.0$.

(ii) Gel filtration I

Of the concentrated culture medium, $10 \mathrm{ml}$ were applied to a Sephadex G-25 column (XK 16/60, $100 \mathrm{ml}$ gel) equilibrated with $20 \mathrm{mM} \mathrm{Na}$ acetate, $\mathrm{pH}$ 5.0. The proteins were eluted at a flow rate of $1 \mathrm{ml} / \mathrm{min}$ and fractions of $10 \mathrm{ml}$ collected.

(iii) Anion-exchange chromatography

Of the active samples from the gel-filtration step, $20 \mathrm{ml}$ were applied to a Q-Sepharose-Fast-Flow ${ }^{\mathrm{TM}}$ column (XK 26/10, 40-ml gel) equilibrated with $20 \mathrm{mM}$ Na acetate, $\mathrm{pH}$ 5.0. The column was washed with the same buffer and the bound proteins eluted at $5 \mathrm{ml} / \mathrm{min}$ by applying an initial 5 -column-volume linear $\mathrm{NaCl}$ gradient up to $0.25 \mathrm{M}$ followed by a 2-column-volume linear $\mathrm{NaCl}$ gradient up to $0.50 \mathrm{M}$. The eluate was collected in $10-\mathrm{ml}$ fractions. The active fractions from the two PG2 peaks were separated and freeze-dried. Both fractions were then processed under the same purification conditions.

(iv) Gel filtration II

The freeze-dried samples were dissolved in a minimum amount of deionized water and poured over a Sephacryl S-100 column (XK $16 / 70,85-\mathrm{ml}$ gel) equilibrated with $\mathrm{Na}$ acetate, $\mathrm{pH} 4.5$ containing $0.15 \mathrm{M} \mathrm{NaCl}$. The column was eluted at $0.5 \mathrm{ml} / \mathrm{min}$ and fractions of $5 \mathrm{ml}$ collected. The active fractions were pooled and dialyzed overnight against $20 \mathrm{mM}$ Na citrate, $\mathrm{pH} 3.0$.

(v) Cation-exchange chromatography

The dialyzed samples were poured onto an SP-Sepharose-Fast-Flow ${ }^{\mathrm{TM}}$ column (XK 16/10, 26-ml gel) equilibrated with $20 \mathrm{mM}$ Na citrate, $\mathrm{pH}$ 3.0. Protein elution was carried out at $3 \mathrm{ml} / \mathrm{min}$ by applying 10 column volumes of $\mathrm{NaCl}$ up to $1.0 \mathrm{M}$. The eluate was collected in 9-ml fractions and the active fractions pooled, desalted against distilled water, and freeze-dried. Chromatographic separations were carried out in an Akta-FPLCTM unit.

Throughout the purification, the PG activity was measured at $\mathrm{pH} 2.2$ in order to monitor the presence of an acid-specific activity in the samples collected.

\subsection{Analytical methods}

Protein concentration was measured by the method of Bradford (Bradford, 1976) with bovine-serum albumin as standard. SDS-PAGE was carried out in a Mighty Small IITM unit (Hoefer SE 260) according to Smith (1984). Isoelectric focussing was performed with an LKB 2117 Multiphor II $^{\mathrm{TM}}$ unit on a 7.5\% (w/v) polyacrylamide gel containing 5\% (v/v) Pharmalyte ${ }^{\mathrm{TM}}(\mathrm{pH} 2.5-5.0)$ according to the manufacturer's instructions. A 3- to-5- $\mu$ g sample of protein was loaded and electrophoresed for $15 \mathrm{~min}$ at $100 \mathrm{~V}, 15 \mathrm{~min}$ at $200 \mathrm{~V}$, and $60 \mathrm{~min}$ at $450 \mathrm{~V}$. The gel was stained with Coomassie Brilliant Blue R-250 for isoelectric-point determination. For localization of the acidic PG activity, in-situ zymogra- 
phy was performed by overlaying the focussing gel with a thin layer of a pectate-agarose gel ( $90 \mathrm{~min}$ incubation at $37{ }^{\circ} \mathrm{C}$ in Na citrate, Na phosphate buffer, $\mathrm{pH}$ 2.2). Then, the pectate-agarose gel was stained with $0.05 \%(\mathrm{w} / \mathrm{v})$ ruthenium red in water. The unstained bands denote the presence of PG2 activity. Periodic-acid-schiff staining to assess the degree of glycosylation of the purified enzyme on the SDS-PAGE gels was carried out as described by Gerard (1990).

\subsection{Enzyme assays}

Unless otherwise stated, PG activity was determined by measuring the release of reducing groups according to the Somogyi-Nelson method (Somogyi, 1952), in a reaction mixture containing $0.2 \%$ (w/v) PGA in a buffer of $50 \mathrm{mM}$ Sodium citrate, $25 \mathrm{mM}$ Sodium phosphate at the indicated $\mathrm{pH}$ and $37^{\circ} \mathrm{C}$. One unit of enzyme activity corresponded to the production of one micromole of reducing sugar as galacturonic acid per min. Activity towards protopectin (i.e., the pectin-solubilizing activity) was carried out at $\mathrm{pH} 2.2$ and $\mathrm{pH} 4.0$ as described elsewhere (Cavalitto et al., 1997).

\subsection{Analysis of hydrolysis products}

Purified exoPGs were used to determine the enzymes hydrolysis products in a reaction mixture containing $0.2 \%(\mathrm{w} / \mathrm{v}) \mathrm{PGA}, 0.05 \%$ $(\mathrm{w} / \mathrm{v} ; 1.3 \mathrm{mM})$ DGA, or $0.07 \%(\mathrm{w} / \mathrm{v} ; 1.3 \mathrm{mM})$ TGA in $20 \mathrm{mM} \mathrm{Na}$ acetate, $\mathrm{pH} 4.0$ with $0.1 \mu \mathrm{g} / \mathrm{ml}$ of enzyme at $37^{\circ} \mathrm{C}$. Aliquots from the reaction mixture were taken at intervals and boiled for $5 \mathrm{~min}$ to inactivate the enzyme. Analysis of the reaction products was carried out by thin-layer chromatography as previously described for endoPG1 (Contreras Esquivel and Voget, 2004) by spotting $2 \mu \mathrm{l}$ of the inactivated sample. The standards of $\mathrm{GA}\left(\mathrm{G}_{1}\right)$ and DGA $\left(\mathrm{G}_{2}\right)$ were spotted at $2 \mu \mathrm{g}$ each and the TGA $\left(G_{3}\right)$ at $5 \mu \mathrm{g}$. The extent of substrate hydrolysis was calculated from the concentration of reducing sugars liberated in the reaction product.

\subsection{Identification of the purified protein by} matrix-assisted-laser-desorption/ionization-time-of-flight mass spectrometry (MALDI-TOF-TOF MS/MS)

For the identification of the components of the purified enzyme in the SDS-PAGE runs by MALDI-TOF/TOF peptide-mass fingerprinting, peptide digests were generated by in-gel treatment with trypsin (Sequencing-grade Promega) overnight at $37^{\circ} \mathrm{C}$. The peptides were extracted from the gel with an aqueous solution of $60 \%(\mathrm{v} / \mathrm{v})$ acetonitrile, $0.2 \%(\mathrm{v} / \mathrm{v})$ trifluoroacetic acid. The resulting solution was then concentrated by evaporation under vacuum and desalted with a C18 reverse-phase microcolumn (Omix pipette tips, Varian). The peptides present in the microcolumn were eluted directly onto the sample plate of the mass spectrometer with $3 \mu \mathrm{l}$ of a solution of $\alpha$-cyano-4-hydroxycinnamic acid in the same $60 \%(\mathrm{v} / \mathrm{v})$ acetonitrile, $0.2 \%$ trifluoroacetic acid. The mass spectrum was measured with a MALDITOF/TOF4800 ${ }^{\mathrm{TM}}$ unit (Applied Biosystems) in reflector mode and calibrated externally by means of a standard peptide mixture (Applied Biosystems). Experiments were performed by collision-induced dissociation MS/MS of the selected peptides. Proteins were identified through the National Center for Biotechnology Information data base from the $m / z$ values of the peptides and the MASCOT program with the following search parameters: monoisotopic mass tolerance, $0.05 \mathrm{Da}$; fragment mass tolerance, $0.25 \mathrm{Da}$; methionine oxidation, as possible modifications, and one missed tryptic cleavage allowed.

\subsection{Properties of the enzymes}

\subsubsection{Effect of $p H$ on exoPG1 and exoPG2 activities}

The effect of $\mathrm{pH}$ on exoPG1 and exoPG2 activities was determined by incubating $0.1 \mu \mathrm{g} / \mathrm{ml}$ of the purified protein at $37{ }^{\circ} \mathrm{C}$ with $0.2 \%$ $(\mathrm{w} / \mathrm{v})$ PGA in $50 \mathrm{mM}$ Na citrate, $25 \mathrm{mM}$ Na phosphate within the $\mathrm{pH}$ range 2.2-6.0 and measuring the release of reducing sugars as mentioned above.

\subsubsection{Effect of $p H$ and temperature on exoPG1 stability}

The enzyme's $\mathrm{pH}$ and temperature stability was studied through the use of a Doehlert design for two variables to represent the combined effects by means of a polynomial model (Doehlert, 1970). Next, a response-surface methodology was applied to represent these effects graphically. The experiments were carried out between pHs of 2 and 7 and temperatures of 30 and $70{ }^{\circ} \mathrm{C}$. The central values were $\mathrm{pH} 4.5$ and $50{ }^{\circ} \mathrm{C}$. Enzymatic stability was evaluated after 2-h incubation in $50 \mathrm{mM}$ Na citrate, $25 \mathrm{mM}$ Na phosphate containing $0.5 \mu \mathrm{g} / \mathrm{ml}$ of the purified protein. To minimize carryover artifacts, the activity assay was performed with samples taken from the same reaction mixture both before and after the incubation under different conditions of $\mathrm{pH}$ plus temperature. The residual activity was measured at the optimum $\mathrm{pH}$ and $37^{\circ} \mathrm{C}$ with the samples having previously been cooled in an ice bath. The stability was expressed as a percent of the initial activity.

\subsubsection{Kinetic parameters}

The kinetic parameters of the purified enzymes were estimated with PGA as substrate at concentrations ranging from 0.5 to $10 \mathrm{~g} / \mathrm{l}$. The activity was measured at $37^{\circ} \mathrm{C}$ in $50 \mathrm{mM}$ Na citrate, $25 \mathrm{mM}$ Na phosphate, $\mathrm{pH}$ 4.0. The kinetic parameters, $\mathrm{K}_{\mathrm{m}}$ and $\mathrm{V}_{\max }$, were calculated by means of the Leverberg-Marquard nonlinear-regression algorithm (Contreras Esquivel and Voget, 2004).

\subsubsection{Effect of cations on exoPG activity}

The effect of several cations $\left(\mathrm{Mg}^{+2} ; \mathrm{Hg}^{+2} ; \mathrm{Zn}^{+2} ; \mathrm{Mn}^{+2} ; \mathrm{Ca}^{+2}\right)$ was tested in the reaction mixture at $\mathrm{pH} 4.0$ and $37^{\circ} \mathrm{C}$, with the enzyme activity being assayed in the presence of $1.0 \mathrm{mM}$ of these cations.

\section{Results and discussion}

\subsection{Purification of the enzymes}

In a previous study from our laboratory the PG2 activity produced by A. kawachii in LP culture was separated into two fractions by anion-exchange chromatography on a 1-ml Resource $\mathrm{Q}^{\mathrm{TM}}$ column. The main fraction, containing about $80 \%$ of the PG2 activity, was attributed to inducible acidic polygalacturonases (Vita et al., 2009). In the present study, through the use of a comparable resin on a larger column and a different elution gradient, the inducible PG2 activity could be resolved into two fractions designated as exoPG1 (the main peak) and exoPG2 (a minor peak), with those eluting at 105-130 mM and 150-230 mM NaCl, respectively (Fig. 1). The additional PG2 fraction, in this instance in peak 3, likely corresponded to endoPG1. This assumption was partially supported by two observations: when the recombinant endoPG1 was mixed with the extract and applied to the column (as an internal standard), the same chromatographic profile was observed but the PG2 activity of peak 3 was increased in proportion to the amount of protein loaded on the column. In addition, a sample of the recom- 


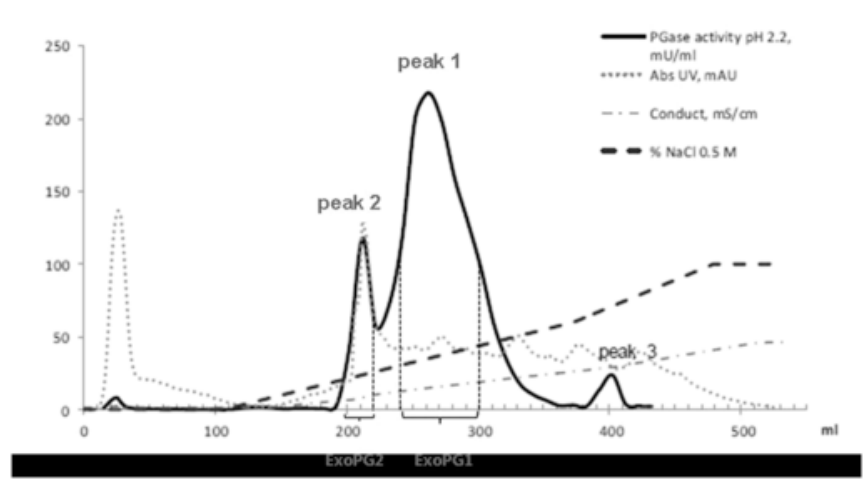

Fig. 1. Elution profile of the exo-PGs produced by A. kawachii in lemon-pomace medium on a Sepharose Q FF column. The column was preequilibrated with $20 \mathrm{mM}$ Na-acetate, $\mathrm{pH}$ 5.0 and next $20 \mathrm{ml}$ of a $20 \mathrm{x}$-concentrated culture filtrate previously equilibrated with the same buffer was applied to the column. The adsorbed proteins were eluted with an initial 5-column-volume linear $\mathrm{NaCl}$ gradient to $0.25 \mathrm{M}$, followed by a 2-column-volume linear $\mathrm{NaCl}$ gradient to $0.5 \mathrm{M}$. Fractions of $10 \mathrm{ml}$ were collected at a flow rate of $5 \mathrm{ml} / \mathrm{min}$ and assayed for PG activity. The vertical lines indicate the fractions collected for subsequent purification of the corresponding exo-PGs. The scale on the ordinate is the same for the four parameters indicated in the key. binant endoPG1, when applied alone, eluted as a unique peak at the same position as the peak 3 in the chromatogram. Table 1 summarizes the results of the purification of the exoPGs. From the fractions collected in this anion-exchange chromatography, the exoPG1 and exoPG2 activities were further purified through Sephacryl S-100 and Sepharose $\mathrm{SP}$ cation-exchange chromatography at $\mathrm{pH}$ 3.0. In both separations the PG2 activity was recovered as single symmetric peaks. The elution peaks from the latter column were centered at $420 \mathrm{mM}$ and $470 \mathrm{mM}$ $\mathrm{NaCl}$ for exoPG1 and exoPG2, respectively (not shown). Analysis by SDS-PAGE of those pooled PG2-activity fractions resulted in a single protein band (Fig. 2), indicating that the acidic exo-PGs had been purified to homogeneity. Nevertheless, the isoelectric-focussing zymogram corresponding to exoPG1 revealed the presence of at least two isoenzymes in the final preparation (Fig. 3). The presence of multiple forms of the same enzyme has been frequently reported for fungal PGases. This multiplicity can result from differences in protein glycosylation or actual genetic variations - e. g., changes in certain amino acids of the polypeptide chain. Isoforms may have the same pattern of kinetic properties as well as $\mathrm{pH}$ optima for the cleavage of PGA, molecular masses, N-termini, and even nearly identical primary sequences though often differing in pI. This microheterogeneity becomes evident when isoelectric-focussing and gel staining for protein and activity is performed (Stratilová et al., 1993; Shanley et al., 1993; Scott-Craig et al., 1998). The whole procedure resulted

Table 1

Summary of purification of exo-PGs from A. kawachii grown on lemon-pomace media.

\begin{tabular}{|c|c|c|c|c|c|c|}
\hline Purification step & Volume & Protein & Activity $\mathrm{pH} 2.2$ & Specific activity & Yield & Purification factor \\
\hline & $(\mathrm{ml})$ & (mg) & (units) & (units/mg) & $(\%)$ & \\
\hline Culture filtrate & 800 & 53.6 & 65.6 & 1.2 & 100 & 1 \\
\hline $\begin{array}{l}\text { Concentration and Sephadex G-25 gel filtration } \\
\text { Sepharose Q FF }\end{array}$ & 80 & 31.0 & 54.9 & 1.8 & 83.7 & 1.5 \\
\hline exoPG1 & 160 & 5.1 & 37.4 & 7.3 & 57 & 6.0 \\
\hline exoPG2 & 80 & 1.1 & 5.7 & 5.2 & 8.7 & 4.2 \\
\hline \multicolumn{7}{|l|}{ Sephacryl S-100 } \\
\hline exoPG1 & 60 & 0.8 & 26 & 32.5 & 39.6 & 26.6 \\
\hline exoPG2 & 36 & 0.3 & 4.6 & 15.3 & 7 & 12.8 \\
\hline \multicolumn{7}{|l|}{ Sepharose SP } \\
\hline exoPG1 & 108 & 0.4 & 18 & 45 & 27.4 & 36.9 \\
\hline exoPG2 & 72 & 0.1 & 3.2 & 32 & 4.9 & 26.2 \\
\hline
\end{tabular}
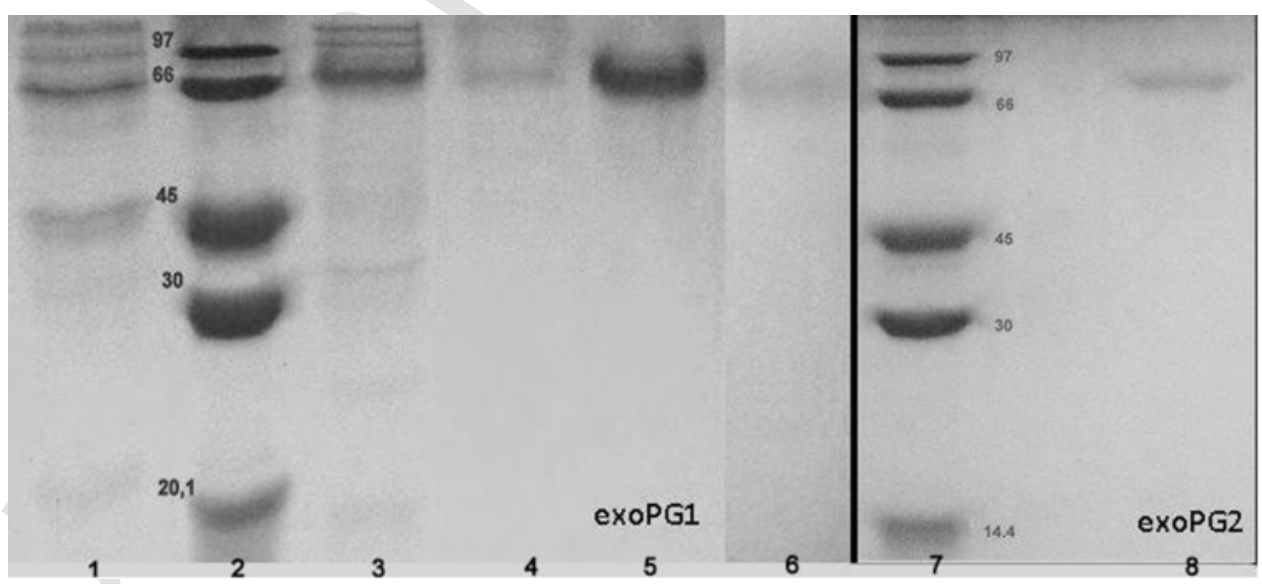

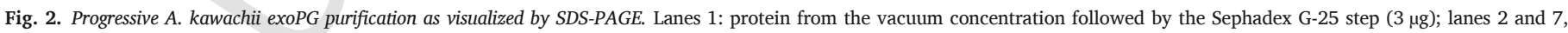

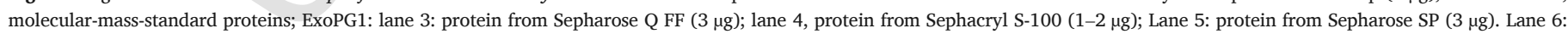
PAS staining of purified exoPG1. Lane 8 ExoPG2: protein from Sepharose SP ( $2 \mu \mathrm{g})$. The gel was stained with Coomassie Brilliant Blue G-250. 


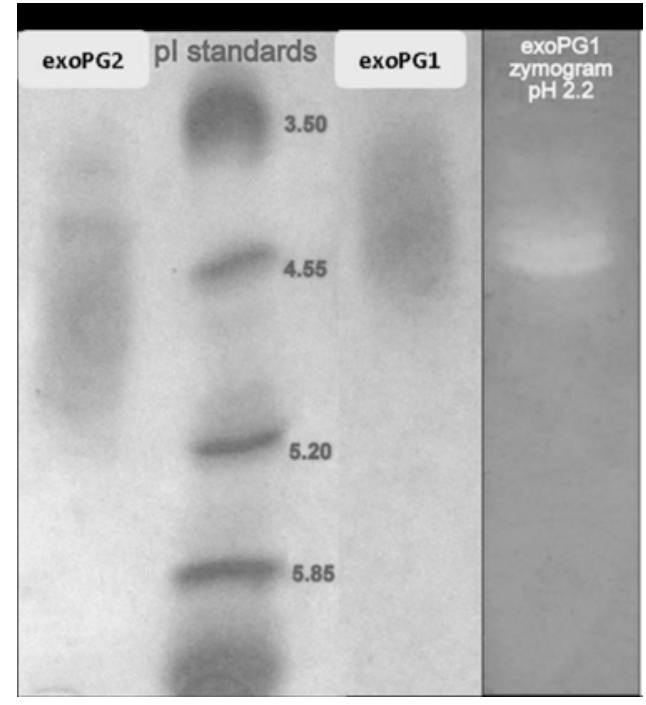

Fig. 3. Isoelectric focussing of A. kawachii exoPG1 and exoPG2. Protein from Sepharose SP $(3 \mu \mathrm{g})$ was loaded onto de gel and electrophoresed as described in M\&M. The gel was stained with Coomassie Brilliant Blue R-250. Zymogram: PG activity was demonstrated by overlaying the focussing gel with a thin layer of a pectate-agarose gel $(90 \mathrm{~min}$ incubation at $37^{\circ} \mathrm{C}$ in Na citrate, Na phosphate buffer, $\left.\mathrm{pH} 2.2\right)$ with ruthenium red $(0.05 \%[\mathrm{w} / \mathrm{v}]$ in water) as the stain.

in a yield of $27.4 \%$ and $4.9 \%$ along with a purification (i.e., the increase in specificity) of 36.9 and 26.2 for exoPG1 and exoPG2, respectively. Since according to the total units recovered after the initial Sepharose-Q chromatography, the exoPG1 activity represented $87 \%$ of the total exoPG activity, this protein may therefore be considered the main acidic exoPG produced by $A$. kawachii under inducing conditions.

\subsection{Characterization of ExoPG1}

The molecular mass of the purified exoPG1 estimated by SDS-PAGE was $75 \mathrm{kDa}$ (Fig. 2, Lane 6). Similarly, the relative molecular mass of the native enzyme determined by gel-filtration chromatography on Sephacryl S-100 was $65 \mathrm{kDa}$, indicating that the enzyme is a monomeric protein. ExoPG1 is glycosylated since the enzyme could be stained with periodic acid schiff in an electrophoresis gel (Fig. 2, Lane 7). The isoelectric point as determined by isoelectric focussing was in the $\mathrm{pH}$ range $4.00-4.65$ (Fig.
The reaction products of exoPG1 with PGA, TGA, and DGA as substrates were analyzed by thin-layer chromatography. Fig. 4A shows that the only product formed by exoPG1 from PGA was GA, thus indicating that the enzyme is specific in hydrolyzing the terminal glycosidic bond of the polymer. A complete hydrolysis of PGA was not obtained even at prolonged incubation times, but after a 24 -h incubation about $50 \%$ of the substrate was hydrolyzed. Similar results were obtained when the initial concentration of PGA was reduced to $0.1 \%(\mathrm{w} / \mathrm{v})$. Although not demonstrated here, the incomplete hydrolysis of PGA may be ascribed to the competitive feedback inhibition of GA (Kester et al., 1996). In contrast, DGA was almost completely hydrolyzed to the monomer within a 2-h incubation (Fig. 4B), as was TGA (Fig. 4C). In this latter instance, the transitory accumulation of DGA observed at the beginning of the hydrolysis suggests that the enzyme degraded the substrate by a mechanism similar to the one described as a multichain attack (Sakamoto et al., 2002). The high efficiency of hydrolyzing DGA and TGA or oligogalacturonates compared to the hydrolysis with PGA has also been reported for other fungal exo-PGs (Kester et al., 1996; Sakamoto et al., 2002). From these results, the hydrolysis of DGA and TGA appears to be less affected by feedback inhibition from GA.

The optimum activity of exoPG1 with PGA as substrate occurred between $\mathrm{pH} 3$ and 4 , with $50 \%$ and $35 \%$ of that maximum occurring at pH 2.2 and 5.0, respectively (Fig. 5). The enzyme hydrolyzes pectin (degree of methylation, 53\%) only marginally and did not solubilize the pectin in lemon pomace under the conditions assayed. In order to determine the enzyme $\mathrm{pH}$ and temperature stability, a Doehlert design was used to represent the combined effects by means of a polynomial model. According to the response surface obtained from the polynomial model (not shown), the observed maximum $\mathrm{pH}$ stability was in the range 4.0-5.0 irrespective of the incubation temperature; whereas the stability decreased as the temperature increased from 30 to $70{ }^{\circ} \mathrm{C}$. By using the equation of the empirical model, the respective calculated exoPG1 stabilities at $\mathrm{pH} 4.0$ after a 2-h incubation at 37,50 , and $60{ }^{\circ} \mathrm{C}$ were $95 \%, 79 \%$, and $54 \%$. Under acidic conditions $(\mathrm{pH} 2.2)$, the residual activity after a 2-h incubation at the same temperatures decreased to $48 \%, 36 \%$, and $16 \%$, respectively. In a previous study, the stability of the A. kawachii endoPG1 had been enhanced by the presence of other molecules, such as proteins (Contreras Esquivel and Voget, 2004). Accordingly, when exoPG1 was incubated in the presence of $100 \mathrm{ppm}$ bovine-serum albumin for $3 \mathrm{~h}$ at $37^{\circ} \mathrm{C}$ and $\mathrm{pH} 2.2$, the enzyme stability increased from $33 \%$ to

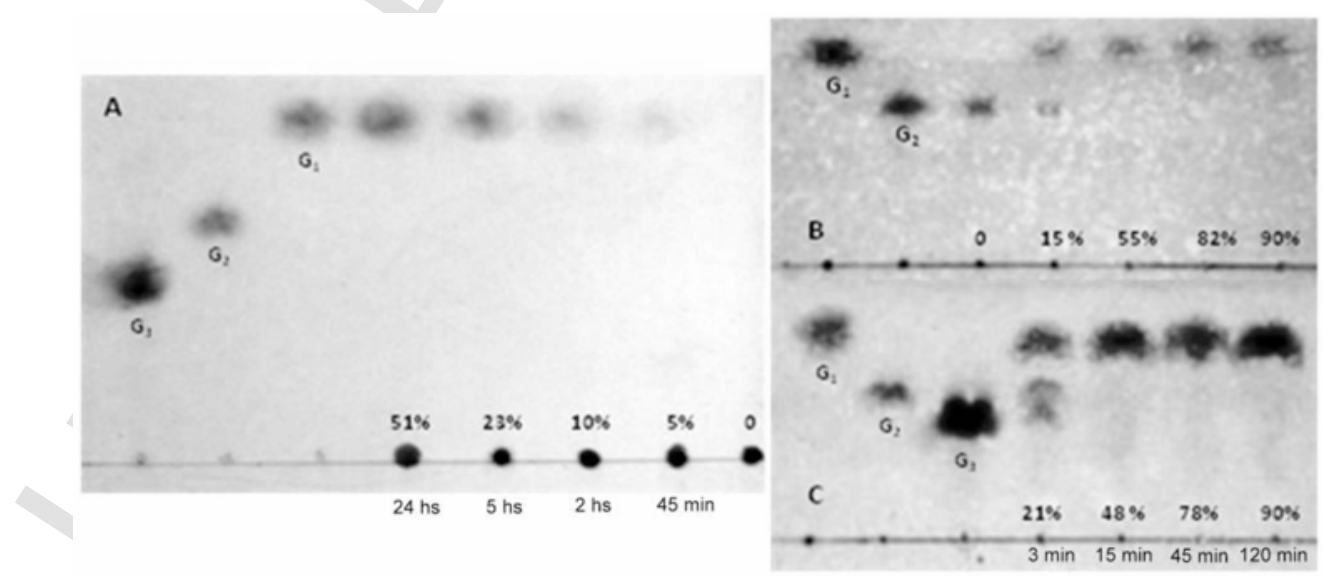

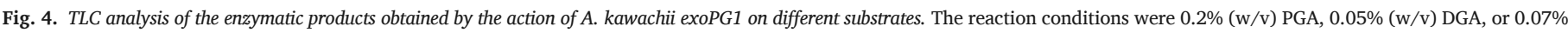

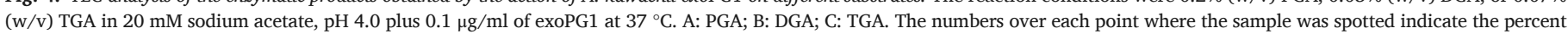
hydrolysis obtained, and the numbers below correspond to the reaction time. 


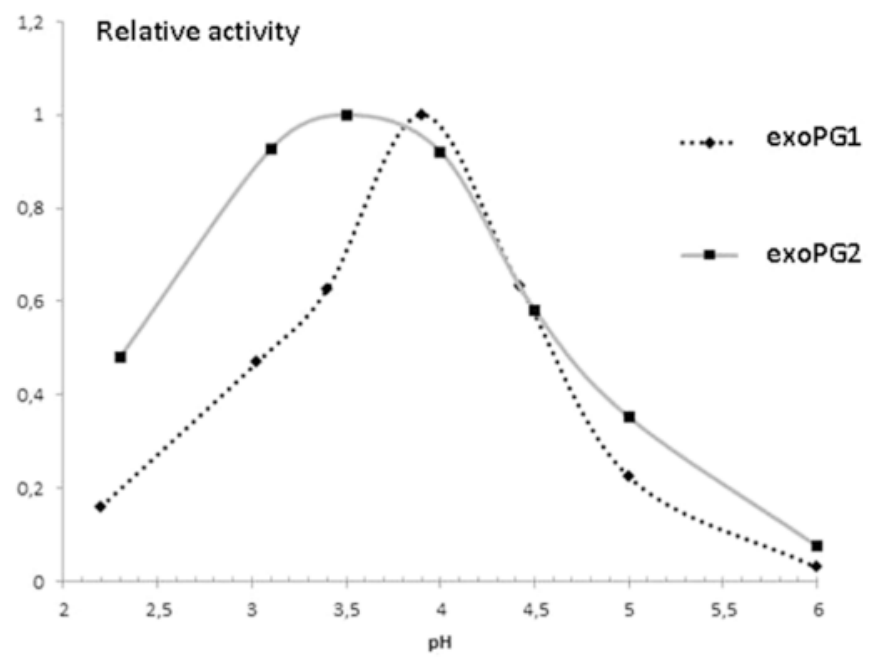

Fig. 5. Effect of $p H$ on A. kawachii exoPG1 and exoPG2 activities. In the figure, the activity relative to that at the optimum is plotted on the ordinate as a function of $\mathrm{pH}$ on the $a b$ scissa.

$66 \%$. The effect of several cations at concentrations of $1.0 \mathrm{mM}$ on enzyme activity was studied in $20 \mathrm{mM}$ Na acetate, $\mathrm{pH}$ 4.0. Whereas $\mathrm{Ca}^{+2}$ and $\mathrm{Mg}^{+2}$ increased enzyme activity by $6 \%$ and $14 \%$, respectively; $\mathrm{Zn}^{+2}$ and $\mathrm{Co}^{+2}$ had no effect on the catalysis. In contrast, $\mathrm{Mn}^{+2}$ and $\mathrm{Hg}^{+2}$ inhibited the enzyme activity by $16 \%$ and $50 \%$, respectively. These results revealed that the exo-PG activity certainly does not depend on those divalent cations for maximal activity. The $\mathrm{K}_{\mathrm{m}}$ and $\mathrm{V}_{\max }$ values for hydrolyzing sodium polypectate at $\mathrm{pH} 4.0$ and $37{ }^{\circ} \mathrm{C}$ were $3.8 \mathrm{mg} / \mathrm{ml}$ and $215 \mu \mathrm{mol} / \mathrm{min} / \mathrm{mg}$ protein, respectively.

\subsection{Characterization of ExoPG2}

The molecular mass of the purified exoPG2 as estimated by SDS-PAGE was $80 \mathrm{kDa}$ (Fig. 2, Lane 8). The isoelectric point as determined by isoelectric focussing was in the $\mathrm{pH}$ range 4.5-5.0 (Fig. 3). Incubation of exoPG2 with PGA gave the same reaction pattern as that shown in Fig. 4A for exoPG1 (not shown). For the reaction with this substrate, a certain degree of product (GA) inhibition also apparently occurred since PGA degradation reached a plateau at about $52 \%$ hydrolysis - a reaction extent nearly identical to that of exoPG1 (i.e., 51\%; Fig. 4A, 24-h incubation). The optimum pH of exoPG2 for the catalysis of PGA was about 4.0; but unlike exoPG1, the activity decreased sharply in the acidic range with only $12 \%$ activity remaining at $\mathrm{pH} 2.2$ (Fig. 5). The effect of cations on enzyme activity was very different from that exhibited by exoPG1; as $\mathrm{Mg}^{+2}$ and $\mathrm{Mn}^{+2}$ did not affect catalysis and $\mathrm{Zn}^{+2}$, $\mathrm{Ca}^{+2}$, and $\mathrm{Hg}^{+2}$ diminished enzyme activity by $15 \%, 40 \%$, and $97 \%$, respectively. The respective $\mathrm{K}_{\mathrm{m}}$ and $\mathrm{V}_{\max }$ values for hydrolyzing sodium polypectate at $\mathrm{pH} 4.0$ and $37^{\circ} \mathrm{C}$ were $5.4 \mathrm{mg} / \mathrm{ml}$ and $174 \mu \mathrm{mol} / \mathrm{min} /$ mg.

\subsection{Hydrolysis of PGA by endo- and/or exoPGs}

Pectin is a complex polymer composed of different structural elements. The GA is derived principally from homogalacturonan, whose carboxyl groups are partially esterified with methanol while certain hydroxyl groups are acetylated (Alphons et al., 2009). A. kawachii converts homogalacturonan to GA through the action of pectin methyl esterase and polygalacturonases (Vita et al., 2009). Neither the exonor the endoPG alone can carry out the complete degradation of PGA. The endoPG generates DGA, which dimer can- not be further hydrolyzed by that enzyme (Contreras Esquivel and Voget, 2004); while the action of the exoPG on the polymer, as mentioned above, is limited to about one-half of the substrate. Nevertheless, since the reaction products generated by endoPG are readily hydrolyzed by exoPG, the combined action of both types of enzymes would be expected to lead to the complete hydrolysis of PGA. To verify this supposition, we incubated PGA with endoPG1 during a short $(1 \mathrm{~h})$ or extended $(24 \mathrm{~h})$ period of time, then added exoPG1 to the reaction mixture (after inactivating the endoPG1 present by boiling) and continued the incubation for up to $24 \mathrm{~h}$. We also carried out a control assay in which PGA was incubated with exoPG1 alone for $24 \mathrm{~h}$. After a 1-h and 24-h incubation with endoPG1 the degree of PGA hydrolysis was $43 \%$ and $75 \%$, respectively, as indicated by thin-layer chromatography of the reaction products (Fig. 6, lanes 5 and 6 , respectively). The main reaction products from catalysis by the recombinant endoPG1 were GA, DGA, and TGA, though higher oligosaccharides were detected transitorily, such as at $43 \%$ hydrolysis (Fig. 6, lane 5). This reaction pattern is the same as that exhibited by the native enzyme (Contreras Esquivel and Voget, 2004). After inactivation of endoPG and subsequent addition of exoPG1, however, the degree of hydrolysis obtained upon a further 24-h incubation was $90 \%$ with GA as the only end product (Fig. 6, lane 7). On the contrary, with exoPG1 alone, PGA hydrolysis was limited to $48 \%$ (Fig. 6 , lane 4). From these results we conclude that the complete hydrolysis of PGA requires the combined action of both the endo- and the exoPG. A simple explanation for this observation is that the endoPG generates products of a low degree of polymerization (like DGA, TGA, and other oligogalacturonates), whose hydrolysis by exoPG is highly efficient and remains essentially uninhibited by the accumulation of GA, such as otherwise occurs when the substrate is the polymeric PGA.

During the growth of the fungus with pectin, the exoPG activity is absolutely necessary for producing the monomer, which species is the essential carbon source (Martens-Uzunova and Schaap, 2008); within this context, however, the inhibition of PGA hydrolysis by GA is probably less relevant, as the monomer disappears from the culture medium through consumption by the fungus. Fig. 7 proposes a simplified mechanism by which $A$. kawachii uses the pectin contained in the plant tissues. Pectin is first solubilized from

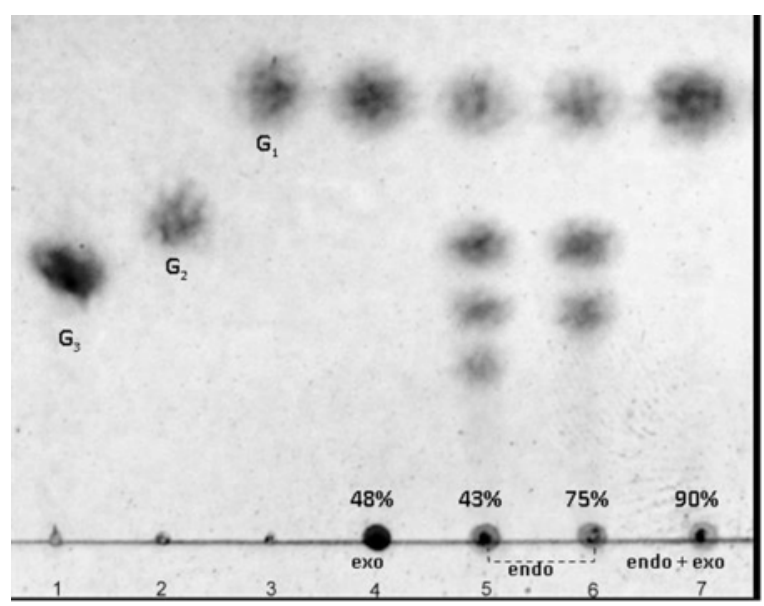

Fig. 6. Hydrolysis of PGA by A. kawachii exoPG1 and recombinant endoPG1. The reaction conditions were as indicated in Fig. 4. Key to notation: enzyme(s), concentration, incubation time. ExoPG1, $0.1 \mu \mathrm{g} / \mathrm{ml}, 30 \mathrm{~h}$; EndoPG1, $0.1 \mu \mathrm{g} / \mathrm{ml}, 1 \mathrm{~h}$ and $24 \mathrm{~h}$; Endo + Exo: EndoPG1 $(0.1 \mu \mathrm{g} / \mathrm{ml}) 24-\mathrm{h}$ and the reaction mixture boiled for 5 min for enzyme inactivation, then exoPG1 $(0.1 \mu \mathrm{g} / \mathrm{ml})$ was added followed by a $24-\mathrm{h}$ incubation. The numbers over each point where the sample was spotted indicate the percent hydrolysis obtained. 


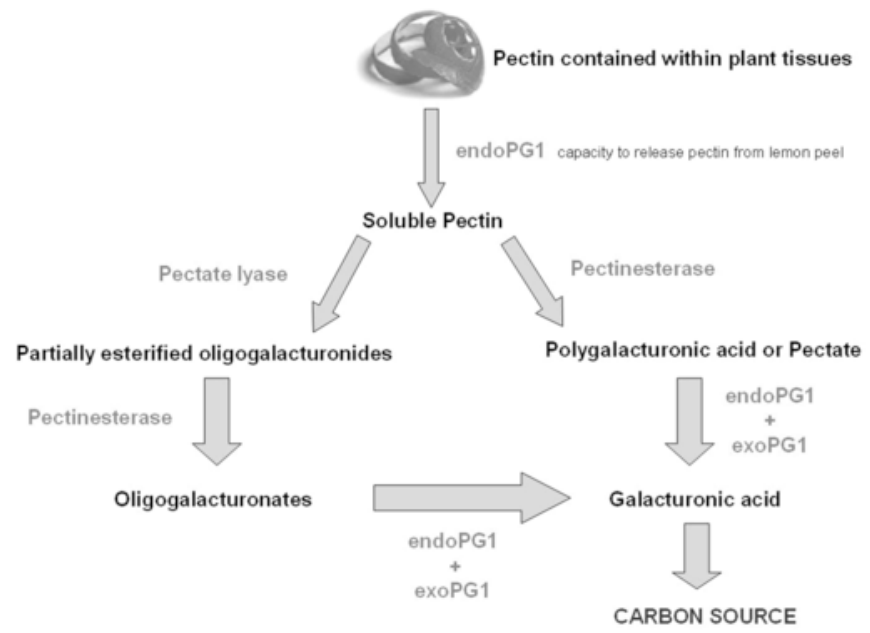

Fig. 7. Schematic representation of the degradation pathway of plant-tissue pectin by the pectinases of $A$. kawachii. PME: pectin methylesterase, PeL: pectin lyase.

protopectin by endoPG1; then the combined action of pectin methylesterase plus the endo- and the exoPG on the homogalacturonan-rich region of the soluble pectin produces the GA that is used as the principal source of carbon and energy for the fungus. As has been pointed out by Martens-Uzunova et al. (2006), exoPGs play a critical role in pectin degradation; and this function may explain the strong expression of the genes encoding these enzymes that they observed after the fungus had been grown in the presence of this C-source. This participation of the exoenzymes is very evident in the example of the fungus Geotrichum klebahnii, which species produces endoPG but either lacks or contains inactive genes encoding exoPGs. The result is that this fungus cannot grow with pectin or PGA as carbon sources but exhibits good growth with AGA (Rojas et al., 2008).

\subsection{Protein identification by peptide-mass fingerprinting}

After trypsin hydrolysis and MALDI-TOF/TOF analysis, a search in the National Center for Biotechnology Information database identified peptide similarities to exoPG1 in the exopolygalacturonase PGXB (UniProtKB/Swiss-Prot: Q27UB1) of A. niger (Martens-Uzunova et al., 2006), the exopolygalacturonase X (exoPGX; UniProtKB/Swiss-Prot: Q00293.1) of Aspergillus tubingensis char- acterized in 1996 by Kester (Kester et al., 1996), the exopolygalacturonase X (GenBank: GAA87642.1) of A. kawachii, and the hypothetical protein deduced from the genomic sequence of this fungus (Futagami et al., 2011). Both these latter proteins are unusual in that they have identical primary sequences. Moreover, the properties of $A$. tubingensis exoPGX and exoPG1 are substantially similar, especially with respect to the molecular mass, the $\mathrm{K}_{\mathrm{m}}$, and the $\mathrm{V}_{\max }$; and both are inducible proteins. We therefore conclude that exoPG1 is most probably identical to the exopolygalacturonase $\mathrm{X}$ of A. kawachii. ExoPG2 likewise presents statistically significant similarities to the exopolygalacturonase C (UniProtKB/Swiss-Prot: Q27UB0) of Aspergillus niger (Martens-Uzunova et al., 2006) and another proposed exopolygalacturonase from A. kawachii (GenBank: GAA84378.1). The properties of the aforementioned exoPGs are summarized in Table 2.

\section{Conclusions}

We report here for the first time the production of exo-polygalacturonases by Aspergillus kawachii. Two inducible exoPGs, namely exoPG1 and exoPG2, were purified from the culture filtrate of $A$. kawachii grown with lemon pomace as the carbon source. ExoPG1 was the more abundant enzyme, as judged by the total activity units measured during the purification process. Both exo-PGs, however, released exclusively monogalacturonic acid from PGA; while exoPG1 also hydrolyzed the di-, tri-, and higher oligogalacturonates to the monomer, though being unable to solubilize pectin from insoluble substrates such as lemon pomace or protopectin. An identification of the purified proteins by MALDI-TOF/ TOF analysis matched two hypothetical proteins deduced from the $A$. kawachii genomic sequence and showed similarities to other Aspergillus exoPGs. ExoPGs are completely necessary for obtaining GA as a carbon source for the fungus from pectin, but this degradation is only possible in combination with the action of endoPGs because of the inability of the exoenzymes to hydrolyze the polymer completely. The activity $v s$. pH profiles of exoPG1 and exoPG2 indicated that the division between acidic and nonacidic $A$. kawachii polygalacturonases, based on their relative activity at pHs 2.0 and 5.0 - that distinction having been previously proposed for the endoPGs - cannot be generalized to these exoenzymes.

\section{Uncited reference}

(Cook et al., 1999).

Table 2

Properties of Aspergillus exo-PGs that showed peptide similarities to A.kawachii exoPGs according to MALDI TOF-TOF MS/MS analysis.

\begin{tabular}{|c|c|c|c|c|c|c|c|c|}
\hline Enzyme & Fungus & $\begin{array}{l}\text { Molecular } \\
\text { mass (kDa) }\end{array}$ & $\mathrm{p} I$ & $\begin{array}{l}\text { Optimum } \\
\text { pH towards } \\
\text { PGA }\end{array}$ & $\mathrm{Km}$ & $\begin{array}{l}\text { Vmax } \\
\text { (units/mg) }\end{array}$ & $\mathbf{K i}^{\mathbf{a}}$ & References \\
\hline & & & & & $(\mathrm{mg} / \mathrm{ml})$ & & (mgGA/ml) & \\
\hline Exo-PG1 & A. kawachii & 75 & $4.0-4.6$ & $3.0-4.0$ & 3.8 & 215 & & This work \\
\hline Exo-PG & $\begin{array}{l}\text { A. } \\
\text { tubingensis }\end{array}$ & 78 & $3.7-4.4$ & 4.2 & 3.2 & 230 & 0.058 & $\begin{array}{l}\text { Kester et al. } \\
\text { (1996) }\end{array}$ \\
\hline Exo-PGXB & A. niger & 67 & & $4.0-4.5$ & & 242 & & $\begin{array}{l}\text { Martens- } \\
\text { Uzunova et al. } \\
(2006)\end{array}$ \\
\hline Exo-PG2 & A. kawachii & 80 & $4.5-5.0$ & 4.0 & 5.4 & 174 & & This work \\
\hline Exo-PGXC & A. niger & 79 & & $3,5-4,0$ & & 223 & & $\begin{array}{l}\text { Martens- } \\
\text { Uzunova et al. } \\
(2006)\end{array}$ \\
\hline
\end{tabular}

a Competitive inhibition. 


\section{Acknowledgements}

This research work was supported by CONICET. SFC and CEV are members of the Research Career of CONICET and CEB hold a fellowship of CONICET. Dr. Donald F. Haggerty, a retired academic career investigator and native English speaker, edited the final version of the manuscript.

\section{References}

Alphons, G., Voragen, J., Coenen, G., Verhoef, R.P., Schols, H.A., 2009. Pectin, a versatile polysaccharide present in plant cell walls. Struct. Chem. 20, 263-275.

Bradford, M.M., 1976. A rapid and sensitive method for the quantitation of microgram quantities of protein utilizing the principle of protein-dye binding. Anal. Biochem. 72, 248-254.

Cavalitto, S.F., Hours, R.A., Mignone, C.F., 1997. Quantification of pectin-releasing activity of protopectinase-SE from Geotrichum klebahnii Biotechnol. Tech. 11, 331-334.

Contreras Esquivel, J.C., Voget, C.E., 2004. Purification and partial characterization of an acidic polygalacturonase from Aspergillus kawachii. J. Biotechnol. 110, 21-28.

Cook B.J. Clay R.P. Bergmann C.W. Albersheim P. Darvill A.G. 1999. Fungal polygalacturonases exhibit different substrate degradation patterns and differ in their susceptibilities to polygalacturonase-inhibiting proteins Mol. Plant Microbe Interact. 12 703-771

Crous, J.M., Pretorius, I.S., van Zyl, W.H., 1995. Cloning and expression of an Aspergillus kawachii endo-1,4-beta-xylanase gene in Saccharomyces cerevisiae. Curr. Genet. 28, 467-473.

Doehlert, D.H., 1970. Uniform shell designs. Appl. Stat. 19, 231-239.

Dunn-Coleman, N., Lantz, S.E., Pepsin, M.J., 2007. Heterologous expression of an Aspergillus kawachii acid-stable alpha amylase and applications in granular starch hydrolysis. 17-4, Google Patents.

Futagami, T., Mori, K., Yamashita, A., Wada, S., Kajiwara, Y., Takashita, H., Omori, T., Takegawa, K., Tashiro, K., Kuhara, S., Oto, M., 2011. Genome sequence of the white koji mold Aspergillus kawachii IFO 4308, used for brewing the Japanese distilled spirit shochu. Eukaryot. Cell 10, 1586-1587.

Gerard, C., 1990. Staining of blotted proteins on membranes, in: Methods in Enzymology. pp. 182-529.

Hara, Y., Hinoki, Y., Shimoi, H., Ito, K., 2003. Cloning and sequence analysis of endoglucanase genes from an industrial fungus, Aspergillus kawachii. Biosci. Biotechnol. Biochem. 67, 2010-2013.

Ito, K., Ogasawara, H., Sugimoto, T., Ishikawa, T., 1992. Purification and properties of acid-stable xylanases from Aspergillus kawachii. Biosci. Biotechnol. Biochem. 56, 547-550.

Iwano, K., Mikami, S., Fukuda, K., Shiinoki, S., Shimada, T., 1986. The properties of various enzymes of shochu koji (Aspergillus kawachii). J. Brew. Soc. Jpn. 81, 490-494.

Iwashita, K., Nagahara, T., Kimura, H., Takano, M., Shimoi, H., Ito, K., 1999. The bglA gene of Aspergillus kawachii encodes both extracellular and cell wall-bound beta -glucosidases. Appl. Environ. Microbiol. 65, 5546-5553.

Iwashita, K., Todoroki, K., Kimura, H., Shimoi, H., Ito, K., 1998. Purification and characterization of extracellular and cell wall-bound beta-glucosidases from Aspergillus kawachii. Biosci. Biotechnol. Biochem. 62, 1938-1946.

Kaneko, A., Sudo, S., Takayasu-Sakamoto, Y., Tamura, G., Ishikawa, T., Oba, T., 1996. Molecular cloning and determination of the nucleotide sequence of a gene encoding an acid-stable a-amylase from Aspergillus kawachii. J. Ferment. Bioeng. 81, 292-298.

Kester, H., Kuster-Van-Someren, M.A., Müller, Y., Visser, J., 1996. Primary structure and characterization of an exopolygalacturonase from Aspergillus tubingensis. Eur. J. Biochem. 240, 738-746.

Kojima, Y., Sakamoto, T., Kishida, M., Sakai, T., Kawasaki, H., 1999. Acidic condition inducible polygalacturonase of Aspergillus kawachii. J. Mol. Catal. B-Enzym. 6, 351-357.

Koseki, T., Mese, Y., Fushinobu, S., Masaki, K., Fujii, T., Ito, K., Shiono, Y., Murayama, T., Iefuji, H., 2008. Biochemical characterization of a glycoside hydrolase family 61endoglucanase from Aspergillus kawachii. Appl. Microbiol. Biotechnol. 77, 1279-1285.

Koseki, T., Mese, Y., Nishibori, N., Masaki, K., Fujii, T., Handa, T., Yamane, Y., Shiono, Y., Murayama, T., Iefuji, H., 2008. Characterization of an alpha-L-rhamnosidase from Aspergillus kawachii and its gene. Appl. Microbiol. Biotechnol. 80, 1007-1013.

Koseki, T., Okuda, M., Sudoh, S., Kizaki, Y., Iwano, K., Aramaki, I., Matsuzawa, H., 2003. Role of two alpha-L-arabinofuranosidases in arabi- noxylan degradation and characteristics of the encoding genes from shochu koji molds, Aspergillus kawachii and Aspergillus awamori. J. Biosci. Bioeng. 96, 232-241.

Kuivanen, J., Mojzita, D., Wang, Y., Hilditch, S., Penttilä, M., Richard, P., Wiebe, M.G., 2012. Engineering filamentous fungi for the conversion of D-galacturonic acid to L-galactonic acid. Appl. Environ. Microbiol. 78, 8676-8683.

Kulbe, K.D., Heinzler, A., Knopki, G., 1987. Enzymatic synthesis of L-ascorbic acid via D-uronic acids; membrane-reactor integrated recovery of D-galacturonic acid from pectin hydrolysates. Ann. N.Y. Acad. Sci. 506, 543-551.

Laurent, P., Razafindralambo, H., Wathelet, B., Blecker, C., Wathelet, J., Paquot, M., 2011. Synthesis and surface-active properties of uronic amide derivatives, surfactants from renewable organic raw materials. J. Surf. Deterg. 14, 51-63.

Martens-Uzunova, E.S., Schaap, P.J., 2008. An evolutionary conserved D-galacturonic acid metabolic pathway operates across filamentous fungi capable of pectin degradation. Fungal Genet. Biol. 45, 1449-1457.

Martens-Uzunova, E.S., Zandleven, J.S., Benen, J.A.E., Awad, H., Kools, H.J., Beldman, G., Voragen, A.G.J., van den Berg, J.A., Schaap, P.J., 2006. A new group of exo-acting family 28 glycoside hydrolases of Aspergillus niger that are involved in pectin degradation. Biochem. J. 400, 43-52.

Mikami, S., Iwano, K., Shiinoki, S., Shimada, T., 1987. Purification and some properties of acid-stable a-amylase from shochu koji (Aspergillus kawachii). Agr. Biol. Chem. 51, 2495-2501.

Morimura, S., Zhang, W., Ichimura, T., Kida, Y., Ibi, Y., Kida, K., 1999. Genetic engineering of white shochu-koji to achieve higher levels of acid-stable á-amylase and glucoamylase and other properties when used for shochu making on a laboratory scale. J. Inst. Brew. 105, 309-314.

Rojas, N.L., Cavalitto, S.F., Mignone, C.F., Hours, R.A., 2008. Role of PPase-SE in Geotrichum klebahnii, a yeast-like fungus able to solubilize pectin. Electron. J. Biotechnol. http://dx.doi.org/10.2225/vol11-issue1-fulltext-13.

Rojas, N.L., Ortiz, G.E., Baruque, D.J., Cavalitto, S.F., Ghiringhelli, D.P., 2011. Production of heterologous polygalacturonase I from Aspergillus kawachii in Saccharomyces cerevisiae in batch and fed-batch cultures. J. Ind. Microbiol. Biotechnol. 38, 1437-1447.

Sakamoto, T., Bonnin, E., Quemener, B., Thibault, J.-F., 2002. Purification and charac terisation of two exo-polygalacturonases from Aspergillus niger able to degrade xylogalacturonan and acetylated homogalacturonan. Biochim. Biophys. Acta 1572, 10-18.

Scott-Craig, J.S., Cheng, Y.Q., Cervone, F., De Lorenzo, G., Pitkin, J.W., Walton, J.D., 1998. Targeted mutants of Cochliobolus carbonum lacking the two major extracellular polygalacturonases. Appl. Environ. Microbiol. 64, 1497-1503.

Shanley, N.A., van der Broek, L.A.M., Voragen, A.G., Coughlan, M.P., 1993. Isolation and characterization of an endopolygalacturonase from Phanerochaete chrysosporium. J. Biotechnol. 28, 179-197.

Smith, B.J., 1984. SDS polyacrylamide gel electrophoresis of proteins. In: Walker, J.M. (Ed.), Methods in Molecular Biology. Humana Press, Clifton, NJ, USA, pp. 41-56.

Somogyi, N., 1952. Notes on sugar determination. J. Biol. Chem. 195, 19-23.

Stratilová, E., Markovic, O., Skrovinová, D., Rexova-Benková, L., Jörnvall, H., 1993. Pectinase Aspergillus sp. polygalacturonase: multiplicity, divergence, and structural patterns linking fungal, bacterial, and plant polygalacturonases. J. Protein Chem. 12, 15-22.

Sujimoto, T., Makita, T., Watanabe, K., Shoji, H., 2012. Production of multiple extracellular enzyme activities by novel submerged culture of Aspergillus kawachii for ethanol. J. Ind. Microbiol. Biotechnol. 39, 605-612.

Tenkanen, M., Viikari, L., Buchert, J., 1997. Use of acid-tolerant xylanase for bleaching of kraft pulps. Biotechnol. Tech. 11, 935-938.

Vita, C.E., Contreras Esquivel, J.C., Voget, C.E., 2009. Pectolytic enzymes of the industrial fungus Aspergillus kawachii. Food Sci. Biotechnol. 18, 1365-1370.

Voget, C.E., Vita, C.E., Contreras Esquivel, J.C., 2006. One-step concentration and partial purification of non-acidic Aspergillus kawachii polygalacturonases by adsorption to glass fiber microfilters. Biotechnol. Lett. 28, 233-239.

Yagi, F., Fan, J., Tadera, K., Kobayashi, A., 1986. Purification and characterization of carboxyl proteinase from Aspergillus kawachii. Agr. Biol. Chem. 50, 1029-1033.

Yoshizaki, Y., Yamato, H., Takamine, K., Ito, K., Sameshima, Y., 2010. Analysis of volatile compounds in shochu koji, sake koji, and steamed rice by gas chromatography-mass spectrometry. J. Inst. Brew. 116, 49-55. 